\title{
Effects of somatostatin analog SOM230 on cell proliferation, apoptosis, and catecholamine levels in cultured pheochromocytoma cells
}

\author{
Daniela Pasquali ${ }^{1}$, Valentina Rossi ${ }^{1}$, Giovanni Conzo², Giuseppe Pannone ${ }^{3}$, Pantaleo Bufo ${ }^{3}$, \\ Annamaria De Bellis ${ }^{1}$, Andrea Renzullo ${ }^{1}$, Giuseppe Bellastella ${ }^{1}$, Annamaria Colao ${ }^{4}$, \\ Gianfranco Vallone ${ }^{5}$, Antonio Bellastella ${ }^{1}$ and Antonio A Sinisi ${ }^{1}$ \\ ${ }^{1}$ Endocrine Unit, Department of Clinical and Experimental Medicine and Surgery and ${ }^{2}$ Endo-Surgery Unit, Second University of Naples, 80131 Naples, Italy \\ ${ }^{3}$ Pathology Section, Department of Surgical Science, University of Foggia, 71100 Foggia, Italy \\ Departments of ${ }^{4}$ Molecular and Clinical Endocrinology and Oncology and ${ }^{5}$ Radiology, 'Federico II' University of Naples, Naples, 80131 Italy
}

(Correspondence should be addressed to D Pasquali who is now at Cattedra di Endocrinologia, Seconda Università di Napoli, Via Pansini 5, Building 16, 80131 Napoli, Italy; Email: daniela.pasquali@unina2.it)

\begin{abstract}
Surgery is the primary therapy for pheochromocytoma (PHEO), a catecholamine-producing tumor. Benign and malignant PHEO could develop recurrences, and the intraoperative risk of recurrent PHEO is an important unresolved issue. Nonsurgical treatments of PHEO recurrence would therefore better prepare patients for reintervention as well as provide them with palliative management. We investigated the effects of the new somatostatin analog (pasireotide) SOM230 versus octreotide (OCT) in primary PHEO cell cultures (Pheo-c). Pheo-c from six benign surgical samples were set up and characterized by immunocytochemistry. Real-time PCR, using both PHEO tissues and Pheo-c, showed different levels of somatostatin receptor ${ }_{1-5}$ mRNA expression. Cells treated with various doses of OCT or SOM230 for 48 and $72 \mathrm{~h}$ were analyzed to assess their effects on cell proliferation and apoptosis and catecholamine levels. Even if reduction of cell viability was observed in Pheo-c treated for $48 \mathrm{~h}$ with either OCT or SOM230 and this effect increased after $72 \mathrm{~h}$, a more significant inhibition of cell growth as well as a significantly higher induction of apoptosis was seen in Pheo-c treated with SOM230 versus OCT. In particular, apoptosis in Pheo-c was detected after $48 \mathrm{~h}$ and was associated with increased expression and activation of caspase-3 and cleaved poly(ADP-ribose) polymerase. OCT $10^{-6} \mathrm{M}$ and SOM230 $10^{-7} \mathrm{M}$ significantly reduced catecholamine levels. Our results indicate that while both OCT and SOM230 modulate cell growth and apoptosis and catecholamine levels in Pheo-c through specific receptors, SOM230 is more effective. This improves our knowledge on the mechanism of SOM230 action in PHEO and supports a possible therapeutic use in benign PHEO recurrence.
\end{abstract}

Journal of Molecular Endocrinology (2008) 40, 263-271

\section{Introduction}

Pheochromocytoma (PHEO) is a catecholamine-producing and -secreting tumor derived from neuroectoderm arising from the adrenal medulla or extra-adrenal neural crest. PHEO, which has an annual incidence of 2-8 per million population (Pacak et al. 2007, Scholz et al. 2007), is generally treated surgically. Both benign and malignant PHEO are at the risk of recurrence, and patients presenting with recurrent disease and repeated interventions are at high risk of perioperative complications (Plouin et al. 2001, Mannelli 2006, Chrisoulidou et al. 2007, Pacak et al. 2007, Scholz et al. 2007). There is no generally effective systemic treatment for PHEO recurrence. Although a considerable proportion of the patients respond to (131)I-meta-iodobenzylguanidine ((131)I-MIBG) radiotherapy or cytotoxic chemotherapy (Chrisoulidou et al. 2007, Pacak et al. 2007), novel agents and approaches are greatly needed to increase the efficacy of current treatment options to better prepare patients for reintervention or to provide them with palliative management. Somatostatin (SS), which acts on both endocrine and non-endocrine tissues, is a key regulator of the release of various hormones and growth factors (Patel 1999). SS exerts its effects by binding to all five SS receptor (sst) subtypes, sst $_{1-5}$. SS analogs have been used in the detection and treatment of different neuroendocrine tumors. For example, octreotide and lanreotide are somatostatin-like oligopeptides that are widely employed in the therapy of somatotropinsecreting pituitary adenomas and neuroendocrine tumors of the gastroenteropancreatic system. In radiolabeled forms (usually 111In-pentetreotide), these analogs are also useful for somatostatin receptor imaging (SRI) (Kaltsas et al. 2001, Chrisoulidou et al. 2007); however, they bind with high affinity to only sst ${ }_{2}$ 
and sst $_{5}$ subtypes (Patel 1999). Although it has been shown that PHEO tissues express more than one sst receptor (Kubota et al. 1994, Mundschenk et al. 2003, Unger et al. 2004, Kolby et al. 2006), only a small amount of conflicting data on the role of OCT for PHEO tumor treatment exists (Invitti et al. 1993, Plouin et al. 1995, Tenenbaum et al. 1995, Kopf et al. 1997, Koriyama et al. 2000, Lamarre-Cliche et al. 2002, Zatelli et al. 2003), and knowledge of the mechanistic action of SS analogs on PHEO remains incomplete. The poor effectiveness of OCT, for example, might be due to only one $\left(\mathrm{sst}_{2}\right)$ of the several sst subtypes expressed in PHEO tissues binding with high affinity to standard somatostatin analogs. Furthermore, immunohistochemical staining has shown that greater than $60 \%$ of PHEO cells express sst $_{3}$ (Unger et al. 2004). Thus, these tumors might represent a potential target for new synthetic analogs active on sst $_{1-3}$ and sst $_{5}$, such as SOM230 (Weckbecker et al. 2002). Whether a subgroup of SRI-positive patients will benefit from new somatostatin analogs with an improved affinity for sst3, such as SOM230, remains to be elucidated. The purpose of this study was to define sst expression in both tissues and cells using an in vitro system of primary cultured PHEO cells derived from surgically removed PHEO tissue of patients affected by benign PHEO, and to investigate the effects of OCT and SOM230 treatment on cell growth control and apoptosis.

\section{Materials and methods}

\section{Cell culture}

Tissue explants were obtained from six patients (aged 25-57 years) after the achievement of presurgical diagnosis of sporadic benign PHEOs by clinical, hormonal, and morpho-functional evaluation. Patients who underwent surgical removal of the adrenal mass gave consent for surgery and for genetic and research studies on tissue specimens. Tissue samples were minced and placed in the lid of a small culture dish with $3 \mathrm{ml}$ dissociation solution: $2 \cdot 6 \mathrm{mg} / \mathrm{ml}$ collagenase type IV, $3 \mathrm{mg} / \mathrm{ml} \mathrm{BSA,} 0 \cdot 15 \mathrm{mg} / \mathrm{ml}$ DNase I, and $0.15 \mathrm{mg} / \mathrm{ml}$ hyaluronidase I-S in Hanks' Balanced Salt Solution (HBSS) at room temperature. Medulla chunks and the solution were recovered and transferred into a Falcon tube using a glass Pasteur pipette. The tube was placed in a thermostatic bath at $37^{\circ} \mathrm{C}$ for $30 \mathrm{~min}$. The solution was gently resuspended every $10 \mathrm{~min}$ with a Pasteur pipette. Over the last $5 \mathrm{~min}$, the solution was continuously resuspended until the medullary tissue became not visible by eye, then stopped to avoid damage of the cells. To stop the enzymatic reaction, cold HBSS was added. The tube containing the digested tissue was placed in the rotor of a pre-cooled $\left(4^{\circ} \mathrm{C}\right)$ refrigerated centrifuge and spinned at $313 \mathrm{~g}$ for $10 \mathrm{~min}$. The pellet was resuspended in pre-warmed Nutrient Mixture F12 Ham/Dulbecco's modified essential medium (dMEM) (vol/vol) supplemented with L-glutamine, $10 \%$ fetal bovine serum (FBS), and antibiotics (GibcoBrl, Life Technologies). To assess the quality of chromaffin cell cultures, the cells were stained with trypan blue solution $(0.2 \%)$ and counted in a hemocytometer chamber to estimate both the yield and the cellular viability. The purity in chromaffin cells of our cultures was estimated by staining the cells with neutral red, a dye that selectively reacts with monoamine-containing cells. Pheo-c was used for experimental protocols at the first and second culture passages, and the experiments were repeated at least thrice.

\section{Immunocytochemistry of Pheo-c}

Cells were grown on four-chamber tissue culturetreated glass slides (Falcon Becton Dickinson, Labware, NJ, USA) pre-coated with poly-L-lysine to enhance cell attachment at a density of 5000 cells per well. Cultured cells were rinsed with PBS, and finally fixed in alcohol.

Immunostaining was performed using the linked streptavidin-biotin horseradish peroxidase technique (LSAB-HRP). Briefly, after hydration, the slides were treated with $0.3 \% \quad \mathrm{H}_{2} \mathrm{O}_{2}$ for $15 \mathrm{~min}$ to quench endogenous peroxidase. Antigen retrieval was performed using microwave heating of the slides immersed in $10 \mathrm{mM}$ citrate buffer $(\mathrm{pH} 6)$, firstly for $3 \mathrm{~min}$ at $650 \mathrm{~W}$, and a second and third time for $3 \mathrm{~min}$ at $350 \mathrm{~W}$. The slides were then blocked for $60 \mathrm{~min}$ with $1.5 \%$ bovine serum (Santa Cruz Biotechnology, Santa Cruz, CA, USA) in PBS buffer before incubating with primary antibody $(\mathrm{Ab})$. Mouse monoclonal $\mathrm{Ab}$ against chromogranin A (AB356M - Biogenex, San Ramon, CA, USA) and mouse monoclonal $\mathrm{Ab}$ against Neuron Specific Enolase (Dakopatts, Dako, Denmark) were diluted 1:100 with $0 \cdot 05 \mathrm{M}$ Tris-HCl buffer $(\mathrm{pH} 7 \cdot 4)$ containing $1 \% \mathrm{BSA}$ and were incubated with samples for $120 \mathrm{~min}$ at $24^{\circ} \mathrm{C}$. Negative control slides without primary antibody were included for each staining condition. After two washes with PBS, the slides were treated with biotinylated species-specific secondary antibodies and streptavidin horseradish peroxidase reagent (LSABHRP, Dako, Denmark), which was followed by color development in 3,3'-diaminobenzidine tetrahydrochloride. Sections were counterstained with Mayer's hematoxylin, and mounted using xylene-based mounting medium. Evaluations of the immunocytochemical staining were performed separately by two observers with at least 10 high power fields using optical microscopy. 


\section{Real-time quantitative RT-PCR}

Total RNA was isolated from tissues and primary cell cultures at early passages (first to second) using TRIZOL (Invitrogen). Before RNA extraction, we washed tissues twice in PBS and macroscopic fibrosis were cut off to avoid contamination by blood cells and to reduce stromal cells. Residual DNA was removed by RNase-free DNase I treatment (Promega). RNAs were reverse transcribed with $5 \mu \mathrm{g}$ total RNA and reverse transcriptase (Superscript-BRL-200 U) as previously described (Sinisi et al. 1997, Pasquali et al. 2000, 2004). We include a total RNA sample that was not reversed transcribed and a no-cDNA control to monitor for genomic DNA contamination or exogenous contamination respectively. The expression of ssts in Pheo-c and PHEO was quantified using the SYBR green reagent $(2 \times$ SYBR Green Supermix, Bio-Rad Laboratories) following the manufacturer's instructions on a Bio-Rad iCycler. PCR was performed in multiplicate under optimized conditions: $95^{\circ} \mathrm{C}$ denaturation for $3 \mathrm{~min}$, followed by 40 cycles of $45 \mathrm{~s}$ at $94{ }^{\circ} \mathrm{C}, 45 \mathrm{~s}$ at $55^{\circ} \mathrm{C}$, and $45 \mathrm{~s}$ at $72^{\circ} \mathrm{C}$ using the following primers: sst $_{1} \quad\left(5^{\prime}\right.$-tgagtcagctgtcggtcatc- $3^{\prime}$ (sense) and $5^{\prime}$-ttggaaagagcgcttgaagt- $3^{\prime}$ (antisense)); sst $_{2}\left(5^{\prime}\right.$-ctttgtggtggtcctcacct- $3^{\prime}$ (sense) and $5^{\prime}$-gcagaggacattctggaagc- $3^{\prime}$ (antisense) $) ; \mathrm{sst}_{3}$ ( $5^{\prime}$-tagggcctacttcccaaggt $-3^{\prime}$ (sense) and $5^{\prime}$-tggcagcaatagcatcaaag- $3^{\prime}$ (antisense) $)$ sst $_{4}$ (5'-cgctcggagaagaaaatca-3' (sense) and $5^{\prime}$-catccagcagagcacaaaga- $3^{\prime}$ (antisense)); sst $_{5}$ $\left(5^{\prime}\right.$-cgccgtcttcatcatctaca- $3^{\prime}$ (sense) and $5^{\prime}$-agcaggtagcacaggcagat $-3^{\prime}$ (antisense)). In these experiments, the amount of specific amplicon present was related to the housekeeping gene, $\beta_{2}$-microglobulin, and subsequently to an internal control. The following primers used were: sense, $5^{\prime}$-ccagcagagaatggaaagtc- $3^{\prime}$ and antisense, $5^{\prime}$-gatgctgcttacatgtctcg- $3^{\prime}$. No other products were amplified because melting curves showed only one peak in each primer pair and only one specific product was observed on agarose ethidium bromide gel for each primer pair. The identity of PCR products was confirmed by comparing the size of the product with the size expected from the gene sequence. Fluorescence signals were measured over 40 PCR cycles. The cycle number was recorded when the signals crossed a threshold set within the logarithmic phase. Data were expressed as the amount of specific PCR products from each gene in cells and in tissues, and were normalized based on the housekeeping gene product $\beta_{2}$-microglobulin (which showed no significant differences between samples). The efficiency of amplification of each pair of primers was determined by serial dilutions of cDNA templates and all were larger than 0.9. Experiments were repeated at least thrice and represented as folds of expression.

\section{Cell proliferation assay}

Cell proliferation was evaluated with the tetrazolium salt (MTT) method as previously described (Pasquali et al. 2000). The MTT Cell Proliferation Assay is a quantitative colorimetric method used to determine cell proliferation. It utilizes the yellow tetrazolium salt (3-(4,5dimethylthiazol-2-yl)-2,5-diphenyltetrazolium-bromide), which is metabolized by mitochondrial succinic dehydrogenase activity of proliferating cells to yield a purple formazan reaction product. The MTT assay is an alternative to the thymidine incorporation test, which measures cell proliferation by determining the amounts of incorporated tritiated thymidine into freshly synthesized DNA. Conversely, when metabolic events lead to apoptosis or necrosis, MTT measures the reduction in cell viability. Briefly, cells were plated in 96-well plates at a density of 2000 cells per well, starved for $24 \mathrm{~h}$ in MEM without FBS, then they were incubated in 1\% FBSsupplemented medium with OCT or SOM230 at $10^{-6} \mathrm{M}$, $10^{-7} \mathrm{M}$, and $10^{-8} \mathrm{M}$ or solvent (control cells) for 48 and $72 \mathrm{~h}$, and then processed according to the manufacturer's instructions. Absorbance was read at $550 \mathrm{~nm}$ using a microtitre plate reader.

\section{Apoptosis detection}

From among the many ways of detecting apoptosis at different stages, we used the most common method called TUNEL (terminal deoxynucleotidyl transferase biotin d-UTP nick end labelling), which identifies apoptotic cells in situ by using terminal deoxynucleotidyl transferase (TdT) to transfer biotin-dUTP to strand breaks of cleaved DNA after the activation of $\mathrm{Ca} / \mathrm{Mg}$-dependent endonucleases in individual apoptotic cells. Cells were plated at $2 \times 10^{6}$ cells $/ 100 \mathrm{~mm}$ Petri dish. The cell monolayers were grown directly on sterilized slides (Superfrost; Carlo Erba, Milan, Italy), starved for $24 \mathrm{~h}$ in dMEM without FBS, and then incubated in 1\% FBS-supplemented medium with OCT or SOM230 at $10^{-7} \mathrm{M}$, or solvent (control cells) for 48-72 h. Using the in situ Cell Death Detection Kit (La Roche, Italy), samples were processed and analyzed as described previously (Pasquali et al. 2000).

\section{Caspase-3 activity}

Caspase-3 enzymatic activity was measured using ApoONE Homogenous Caspase-3 Assay (Promega). Briefly, Pheo cells were seeded in 96-well plates (50 000 cells/ well) and treated with or without octreotide, and SOM230 (at $10^{-8}, 10^{-7}, 10^{-6} \mathrm{M}$ ) for $48 \mathrm{~h}$ at $37^{\circ} \mathrm{C}$, in DMEM (Sigma Chemical) supplemented with $10 \%$ FCS. The timing of treatment was determined on the basis of preliminary experiments carried out at different time intervals showing the maximal stimulation at $48 \mathrm{~h}$. Experiments were repeated at least twice and each determination was done in quintuple. 


\section{Electrophoresis and western blot analysis}

Lysates of Pheo-c treated with $10^{-7}$ M OCT or SOM230 for $48 \mathrm{~h}$ were subjected to gel electrophoresis followed by immunoblotting using polyclonal antibody anti-caspase3 (H-277), and mouse monoclonal IgG $200 \mu \mathrm{g} / \mathrm{ml}$ antipoly ADP-ribose polymerase(PARP)-1 (F-2) (Santa Cruz Biotechnology, Inc.) at working concentrations of 1:200 and 1:500 respectively. Western blot analysis was done as reported previously (Pasquali et al. 2000).

\section{Determination of intracellular catecholamine levels}

Catecholamine levels were determined in medium collected from cells, starved for $24 \mathrm{~h}$ in dMEM without FBS, and in the absence (control) or presence of OCTand SOM230 $10^{-8} \mathrm{M}, 10^{-7} \mathrm{M}, 10^{-6} \mathrm{M}$ for 24 , by highpressure liquid chromatography (HPLC) with electrochemical detection. A $12.5 \mathrm{~cm}$ long, $5 \mu \mathrm{m}$ C-18 reverse phase column (Waters Chromatography Division, USA) was connected to a carbon electrode set at a potential of $+0 \cdot 75 \mathrm{~V}$ relative to the $\mathrm{Ag} / \mathrm{AgCl}$ reference electrode, in turn connected to an LC-4 amperometric detector (Bioanalytic System Inc., West Lafayette, IN, USA) in the HPLC system. The detection limit for catecholamines, defined as a peak height to noise ratio greater than 2 , was $40 \mathrm{pg}$. The mobile phase consisted of $1.75 \mathrm{~g}$ heptanesulfonic acid, $0 \cdot 1 \mathrm{~g}$ disodium EDTA, $3 \cdot 5 \mathrm{ml}$ triethylamine, $4 \mathrm{ml}$ phosphoric acid, and $40 \mathrm{ml}$ acetonitrile made up to 11 in distilled water and was filtered and degassed just prior to use. External standards of dopamine and norepinephrine were dissolved in $0 \cdot 1 \mathrm{M}$ perchloric acid and run simultaneously with each experiment. The protein content of the tissue pellets solubilized in $0.5 \mathrm{M}$ $\mathrm{NaOH}$ was assayed by the method of Lowry.

\section{Statistical analysis}

The data were reported as mean \pm s.E.M. from at least three separate experiments performed in triplicate. The means were compared using ANOVA. Differences in expression of sst $_{1-5}$ in PHEO tissues or Pheo cells evaluated by real-time PCR were determined using one-way ANOVA followed by a Neuman-Keuls post hoc analysis.

\section{Results}

\section{Immunocytochemical identification of PHEO cells in primary culture}

Ultrastructural analysis of PHEO shows that the cells contain numerous neurosecretory-type dense-core granules containing norepinephrine and epinephrine. Immunohistochemical analyses of PHEO tissues always show reactivity for chromogranin, neuron-specific enolase, as well as catecholamines, catecholaminesynthesizing enzymes, synaptophysin, and opioid peptides. We therefore used specific monoclonal antibodies designed for the immuno-localization of chromogranin A and neuron-specific enolase (NSE). PHEO cells in primary culture (Pheo-c), which were processed for immunocytochemical analysis, stained positively in a granular pattern with the antibody against chromogranin A (Fig. 1A), and NSE (Fig. 1B). Morphological assessments by pathologists and the strong immunoreactivities of the specific neuroendocrine markers have convinced us that the cells cultured are selected chromaffin cells, and we thus excluded the possibility of contaminating material.
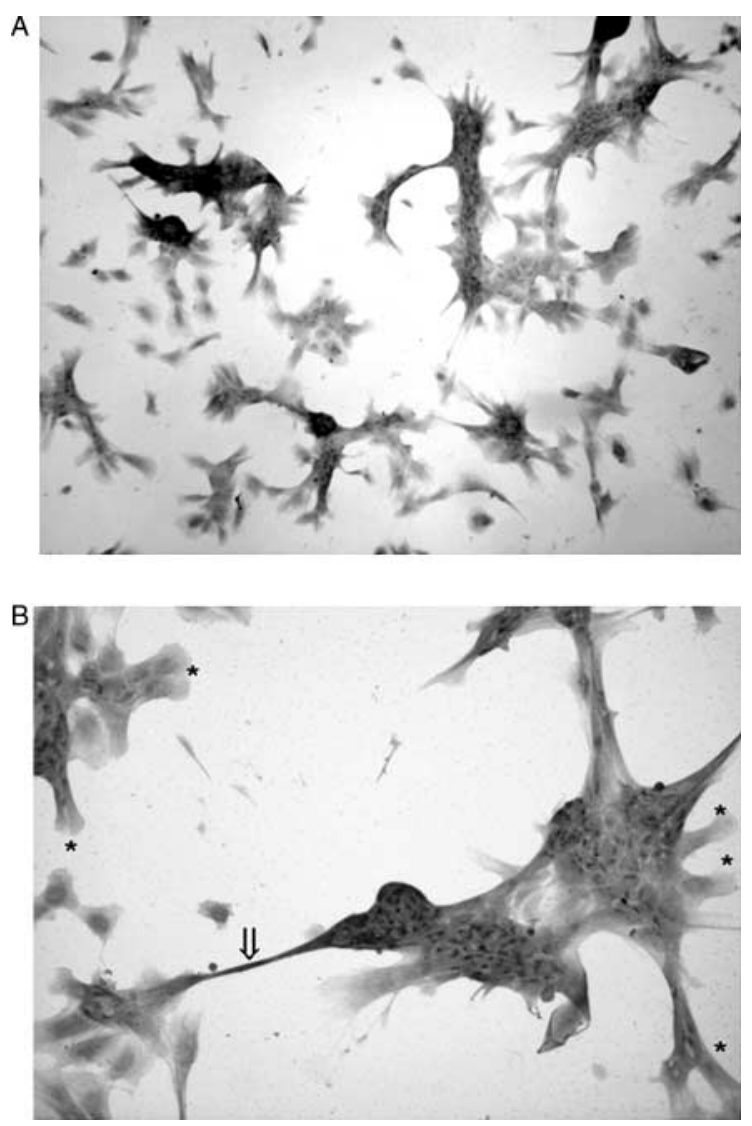

Figure 1 Strong cytoplasmic immunoreactivity for (A) chromogranin $A$ and $(B)$ neuron-specific enolase in cultured PHEO cells. These cells show nuclear pleomorphism and hyperchromatism, and mimic neuronal and ganglion cells with cytoplasmic extensions similar to neuritic $(\Downarrow)$ and dendritic (asterisk) processes. The immunoreaction with the specific antibodies, and the morphological characteristics demonstrate the nature of pheochromocytoma cells (LSAB-HRP, original magnification (A) $\times 100$ and $(B) \times 400$; nuclear counterstaining with hematoxylin; for further details see Materials and methods). 
Table 1 Somatostatin receptor (sst) subtype mRNA expression in six pheochromocytoma tissues and in corresponding primary cell cultures

\begin{tabular}{|c|c|c|c|c|c|}
\hline & sst $_{1}$ & sst $_{2}$ & sst $_{3}$ & sst $_{4}$ & sst $_{5}$ \\
\hline PHEO 1 & + & + & - & + & + \\
\hline PHEO 2 & + & + & + & + & + \\
\hline PHEO 3 & + & + & + & - & + \\
\hline PHEO 4 & + & + & + & + & + \\
\hline PHEO 5 & - & + & + & + & + \\
\hline PHEO 6 & + & + & + & + & + \\
\hline Pheo-c 1 & + & + & - & + & + \\
\hline Pheo-c 2 & + & + & + & + & + \\
\hline Pheo-c 3 & + & + & + & - & + \\
\hline Pheo-c 4 & + & + & + & + & + \\
\hline Pheo-c 5 & - & + & + & + & + \\
\hline Pheo-c 6 & + & + & + & + & + \\
\hline
\end{tabular}

PHEO 1, 2, 3, 4, 5, and 6, pheochromocytoma tissues; Pheo-c 1, 2, 3, 4, 5, and 6, pheochromocytoma cell cultures. +, mRNA present; -, mRNA absent.

\section{PHEO tissue and primary cultured cell expression of sst genes}

In order to further characterize our various tissue samples and the in vitro cell system used, we studied the expression pattern of sst, which would be useful for explaining potential differences of SOM230 and OCT action on Pheo-c. Transcripts of the ssts family were differentially expressed in PHEO tissues and Pheo-c cells. In all tissues and cultures studied, the $\mathrm{sst}_{2}$ and $\mathrm{sst}_{5}$ mRNAs were found (Table 1). However, $\mathrm{sst}_{1}, \mathrm{sst}_{3}$, and sst $_{4}$ were absent in PHEO5, PHEO1, and PHEO3 respectively and their corresponding cultured cells, demonstrating the heterogeneity which can exist in these neuroendocrine cells (Table 1). Furthermore, real-time PCR analysis using $\mathrm{PHEO}$ tissue samples and Pheo-c cultures showed that $\mathrm{sst}_{2}$ was the dominant receptor expressed in these samples (Fig. 2).

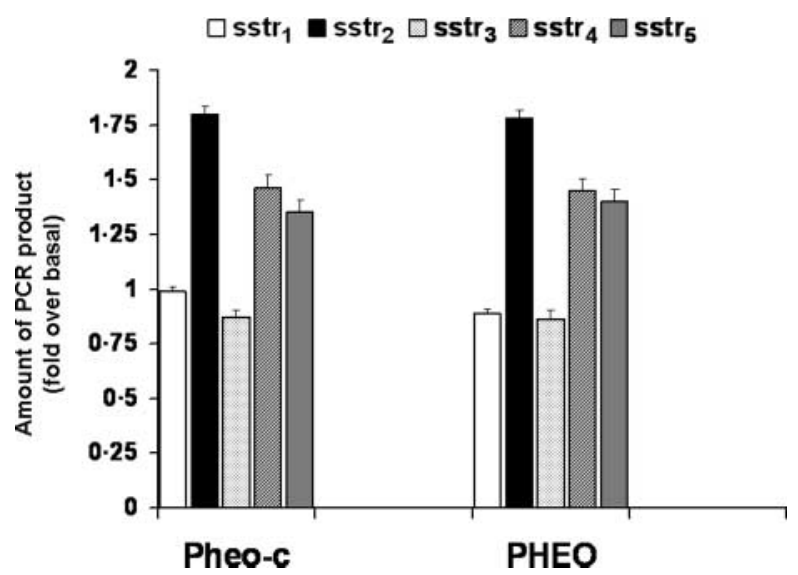

Figure 2 Evaluation of the expression level of $\mathrm{sst}_{1-5}$ in three PHEO tissues and primary cell cultures of pheochromocytoma. Real-time PCR products of $\mathrm{sst}_{1-5}$ were normalized to a housekeeping gene product in each experiment $\left(\beta_{2}\right.$-microglobulin). Data are the mean \pm S.E.M. $(n=6)$.

\section{In vitro effects of octreotide and SOM230 on cell viability}

Cells were seeded at 2000 cells per well, and treated with $10^{-8} \mathrm{M}, 10^{-7} \mathrm{M}$, and $10^{-6} \mathrm{M}$ OCT or SOM230 for 48 and $72 \mathrm{~h}$. Pheo-c cell growth was inhibited after $48-\mathrm{h}$ treatment with $10^{-7}$ and $10^{-6} \mathrm{M}$ SOM230 $(P<0 \cdot 05$ and $P<0.001$ respectively), while only a significant reduction in cell viability was seen using $10^{-6} \mathrm{M}$ OCT (Fig. 3A). This effect was even greater after 72-h exposure to either compound. As shown in Fig. 3B, OCT and SOM230 at $10^{-7} \mathrm{M}$ increased the TUNELpositive process in cultured cells after 48-h treatment ( $8 \%$ and $16 \%$, respectively). Induction of the apoptoticrelated event was significantly higher in Pheo-c treated with SOM230 versus OCT $(P<0 \cdot 01)$.

\section{Caspase-3 and poly (ADP-ribose) polymerase levels}

We studied the effect of OCT and SOM230 on the cellular apoptotic protein markers caspase- 3 and proteolytic cleavage products of PARP-1. Western blot analysis of cells that were treated with $10^{-7} \mathrm{M}$ OCT or SOM230 for $48 \mathrm{~h}$ revealed a significant increase in the expression of the $32 \mathrm{kDa}$ caspase-3 protein (Fig. 4A) and activity (Fig. 5). In cultured cells obtained from all PHEO tissues, OCT and SOM230 induced a dosedependent increase in caspase-3 activity that was detected at concentrations higher than $10^{-8} \mathrm{M}$ (data not shown) and maximal at $10^{-7} \mathrm{M}(178 \pm 20 \%$ and $180 \pm 20 \%$ respectively versus basal) (Fig. 5). PARP-1 is a nuclear enzyme involved in DNA repair and is specifically digested into 89 and $24 \mathrm{kDa}$ fragments by caspase-3 during the apoptotic process (Soldani \& Scovassi 2002). After treatment of Pheo-c with $10^{-7} \mathrm{M}$ OCT or SOM230 for $48 \mathrm{~h}$, an increase was seen in 113 kDa PARP-1 protein compared with control cells, and in addition, 89 kDa fragment was present (Fig. 4B). 

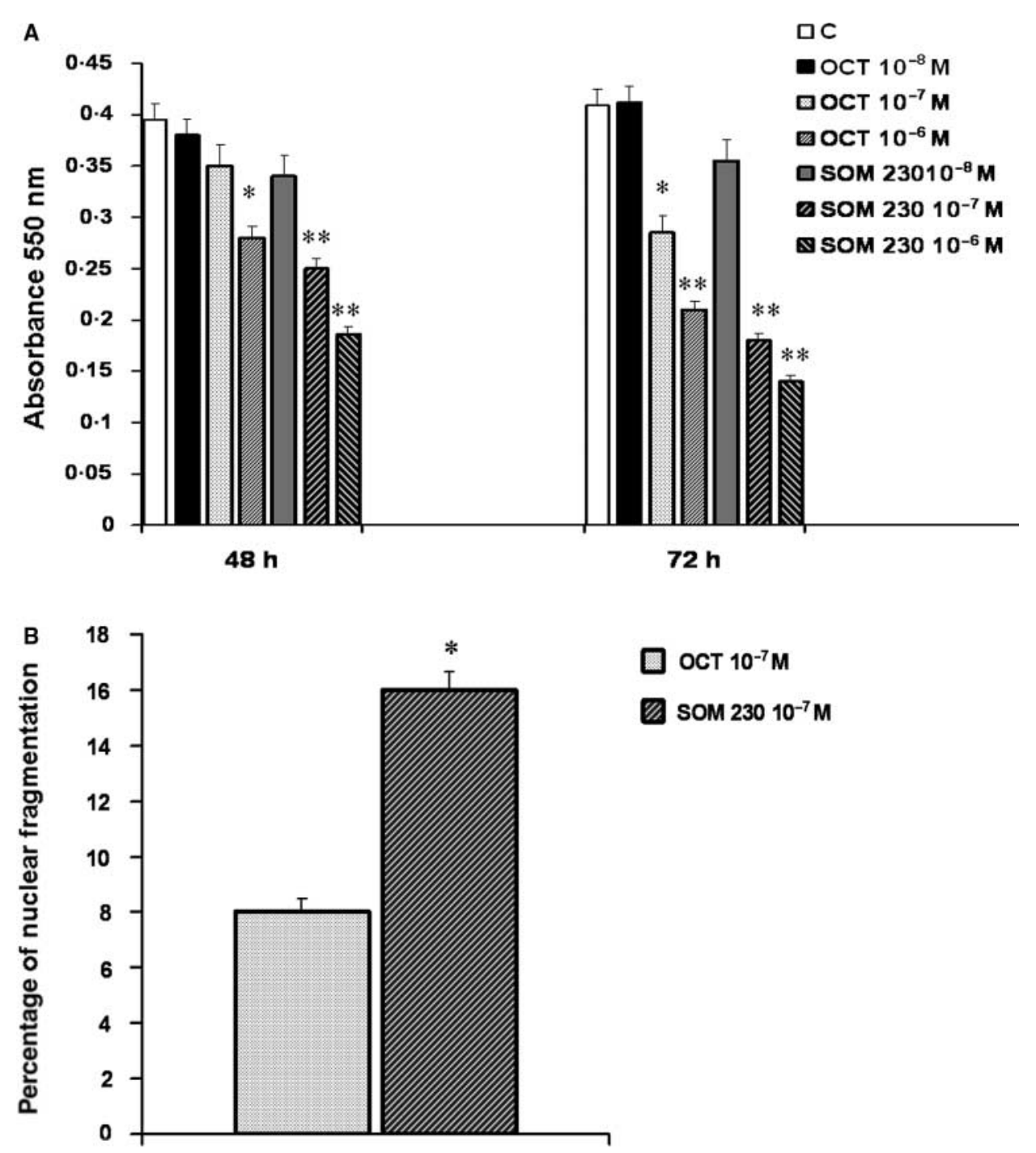

Figure 3 (A) Octreotide (OCT) and SOM230-induced growth inhibition in human pheochromocytoma cells. Cells were seeded at 2000 cells per well and treated with $10^{-8} \mathrm{M}, 10^{-7} \mathrm{M}$, and $10^{-6} \mathrm{M}$ OCT or SOM230 for 48 and $72 \mathrm{~h}$. Results were expressed as the A550 of MTT-derived formazan developed by untreated control and treated cells. Each point represents the mean \pm of three separate experiments $\left({ }^{\star} P<0 \cdot 05\right.$; $\left.{ }^{\star \star} P<0 \cdot 001\right)$. (B) Octreotide (OCT) and SOM230-induced apoptosis of human pheochromocytoma cells. Cells were treated with $10^{-7} \mathrm{M} \mathrm{OCT}$ and SOM230 for $48 \mathrm{~h}$. Following treatment, apoptosis was detected by TUNEL method. Values represent the mean of three independent experiments performed in duplicate ( \pm S.E.M.) $\left({ }^{\star} P<0.01\right)$.

Thus, the apparent enzymatic digestion of PARP-1 shown here is a further evidence for the caspasedependent apoptotic induction by these compounds.

\section{Effects of octreotide and SOM230 on intracellular catecholamine levels}

PHEO cells were treated with octreotide and SOM230 at different doses for $24 \mathrm{~h}$ to examine the intracellular catecholamine levels by HPLC. As shown in Table 2 $10^{-8} \mathrm{M}$ octreotide and SOM230 had no effect on intracellular catecholamine levels. At $10^{-7} \mathrm{M}$ and over, SOM230 significantly inhibited the intracellular dopamine and norepinephrine levels $(P<0 \cdot 05$ and $P<0 \cdot 01$ respectively). Octreotide induced a significant reduction of catecholamine levels only at the higher doses.

\section{Discussion}

In order to gain further mechanistic insights into the responses of PHEO to compounds which could interact via somatostatin receptors (sst), this study was aimed at 


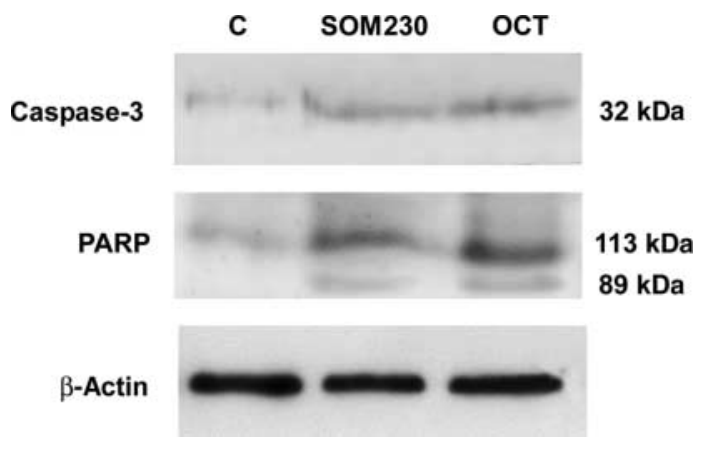

Figure 4 Octreotide (OCT)- and SOM230-induced expression of apoptotic protein markers in human pheochromocytoma cells. Western blot analysis of caspase-3, and cleaved PARP $(25 \mu \mathrm{g}$ protein loaded per lane). Western blot analysis revealed that treatment with $10^{-7} \mathrm{M}$ OCT or SOM230 for $48 \mathrm{~h}$ significantly increased the expression of caspase-3 and cleaved PARP in Pheo-c. The blots are representative of four independent experiments. $\beta$-actin was included to control for loading.

characterizing the sst subtypes in tissues and cells from benign PHEO and testing the in vitro activity of a relatively new analog of somatostatin, SOM230, comparing its effects with the analog OCT on inhibition of cell growth, induction of apoptosis and reduction of catecholamine levels in primary cultures of PHEO cells.

To characterize our PHEO cells in culture, specific antibody against chromogranin A was used for immunocytochemistry because this protein, in combination with other specific neuroendocrine markers, such as NSE, is useful for appropriate neuroendocrine morphologic identification. Chromogranins A, B, and C, a group of monomeric, acidic polypeptides of various sizes that compose the major portion of soluble protein extracts of neurosecretory granules from neuroendocrine cells,

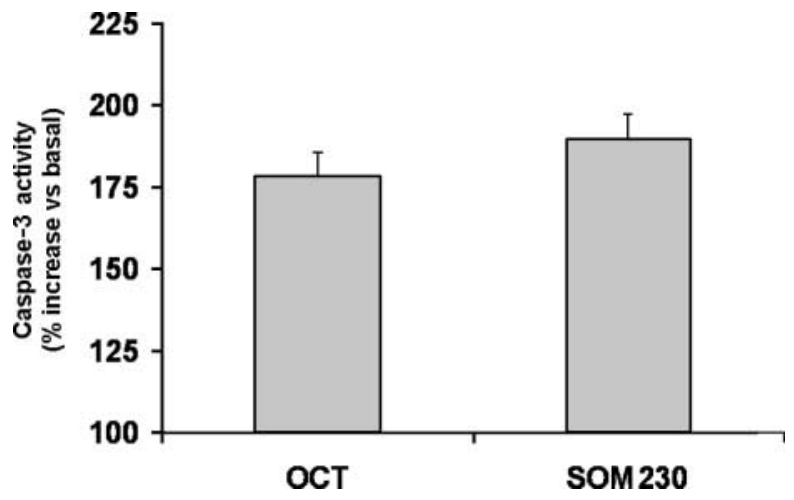

Figure 5 Effects of somatostatin analogs on apoptosis in human pheochromocytoma cells: octreotide (OCT) and SOM230 induced an increase in caspase-3 activity that was maximal at $10^{-7} \mathrm{M}$ at 48-h treatment. Experiments were repeated at least twice and each determination was done in quintuplicate. Data represent the percent increase (mean \pm S.E.M.) of both caspase-3 activity over basal value, arbitrarily defined as $100 \%$, in six Pheo-c. have proved to be a widespread histological marker for polypeptide-producing cells, the adrenal medulla, and tumors derived from them. The largest of these polypeptides is chromogranin A; the plasma concentration of this substance is usually elevated in PHEO, a feature of great diagnostic utility. The enolase enzymes comprise five different forms, each of which is composed of three homodimers and two hybrids. The cultured PHEO cells showed the presence of both chromogranin A and NSE (Fig. 1).

The first point emerging from our data is that both PHEO and Pheo-c expressed sst subtypes with large heterogeneity similar to that observed by previously published data (Kubota et al. 1994, Mundschenk et al. 2003, Zatelli et al. 2003, Unger et al. 2004, Kolby et al. 2006). PHEO tissues and Pheo-c from the same patient did not show different pattern of sst, in spite of blood vessels, fibroblasts, and other stromal cells that could be present in tissues. This could be explained considering the extreme accuracy in the collection of the sample immediately after surgery; a further possible explanation could be that each tumor has its own pattern of sst, which is the same in all compartments.

The most remarkable result of our study is that both OCT and SOM230 affect cell growth and apoptosis and catecholamine levels, but SOM230 was more effective than OCT. For example, SOM230 at concentrations of $10^{-6} \mathrm{M}$ and $10^{-7} \mathrm{M}$ caused inhibition of cell growth in Pheo-c after $48 \mathrm{~h}$, while only the higher dose of OCT $\left(10^{-6} \mathrm{M}\right)$ was effective; this inhibition persisted after 72-h treatment with either compound. Moreover, SOM230 induced a significant increase in apoptotic cells compared with OCT. Even if concentrations of OCT and SOM230 $\left(10^{-6}\right.$ and $\left.10^{-7} \mathrm{M}\right)$ necessary to affect cell proliferation and apoptosis could be considered high, they were the same doses used for functional studies with OCT in our previous in vitro cell culture studies (Pasquali et al. 2000). Furthermore, we showed that SOM230 markedly suppressed intracellular catecholamine levels (Table 2), suggesting that it could inhibit catecholamine biosynthesis.

PHEO, which belongs to a heterogeneous group defined as neuroendocrine tumors (Barakat et al. 2004), is generally treated surgically. Although prognosis after tumor resection is excellent, a significant proportion of PHEOs may recur, some as metastases. Thus, appropriate follow-up is mandatory, and recurrence of PHEO is a key problem needing particular attention. Treatment with metyrosine with or without phenoxybenzamine might help to control blood pressure and alleviate symptoms, but it has no effect on tumor size (Steinsapir et al. 1997). Palliative management comprising of chemotherapy and/or therapeutic doses of MIBG has only limited effects on tumor growth, and patients with malignant PHEO might not take up MIBG (Sisson \& Shulkin 1999, 
Table 2 Effects of octreotide (OCT) and SOM230 on intracellular catecholamines content

\section{Dopamine (ng/mg protein)}

Norepinephrine (ng/mg protein) SOM230

\section{OCT}

None

$10^{-8} \mathrm{M}$

$10^{-7} \mathrm{M}$

$10^{-6} \mathrm{M}$

$\begin{array}{ll}2260 \pm 89 & 920 \pm 31 \\ 2245 \pm 76 & 934 \pm 26 \\ 2180 \pm 50 & 863 \pm 14 \\ 1821 \pm 61^{*} & 512 \pm 13^{*}\end{array}$

SOM230

Dopamine (ng/mg protein)

None
$10^{-8} \mathrm{M}$
$10^{-7} \mathrm{M}$
$10^{-6} \mathrm{M}$

Norepinephrine ( $\mathrm{ng} / \mathrm{mg}$ protein)

$989 \pm 35$

$954 \pm 29$

$523 \pm 18^{*}$

$459 \pm 19^{*}$

Significantly different from control: ${ }^{*} P<0.01,{ }^{\dagger} P<0.05$.

van der Harst et al. 2001, Scholz et al. 2007). For endocrine tumors, somatostatin (SS) and its receptors are classical tools for diagnosis, long-term treatment with no radioactive analogs, and for radiotherapy using, for example, 90YDOTA-d-Phe-Tyr-octreotide (Bruns et al. 1996). Pharmacological therapy with SS analogs has dramatically improved symptom control, proving helpful to stabilizing neuroendocrine tumor progression by inhibiting specific growth factors such as IGF-I and angiogenesis (Patel 1999). SS binds to the five known SS receptor subtypes, $\mathrm{sst}_{1-5}$, with high affinity, whereas the SS analogs used clinically (OCT and lanreotide), bind preferentially and with high affinity to only sst 2 (Patel 1999, Hannon et al. 2002). Recently, SOM230, a new synthetic SS analog, has been shown to bind four out of five sst receptors, with high affinity for $\mathrm{sst}_{1}, \mathrm{sst}_{2}$, and in particular for $\mathrm{sst}_{5}$, which is 40 times greater than OCT, and even improved over SS. This peculiar capacity of SOM230 may be crucial for its inhibitory effects (Weckbecker et al. 2002). Our results indicate that both PHEO tissues and Pheo-c express more than one of the genes coding for known SS receptor subtypes with high $\left(\mathrm{sst}_{2}\right)$ or intermediate $\left(\mathrm{sst}_{5}\right)$ affinity for the analog OCT. Moreover, we also detected mRNA for $\mathrm{sst}_{1}$, which has high affinity for SOM230, and is not always found in PHEO (Unger et al. 2004). Interestingly, sst $_{3}$ mRNA, which is reported to be very frequently expressed in PHEO (Zatelli et al. 2003, Unger et al. 2004), was absent in PHEO 1 and its cell culture Pheo-c 1. The observations of both inhibition of cell growth and programmed cell death induction suggest that intracellular signal transduction pathways, activated by $\mathrm{SS}$ analog interactions with $\mathrm{sst}_{2}$ and $\mathrm{sst}_{5}$, are functional in Pheo-c. Different cell death mechanisms control many physiological and pathological processes in humans. Caspases are a family of cysteine-aspartate proteases that are synthesized as inactive proenzymes. Activated caspase- 3 contributes to apoptosis by cleaving substrate proteins (Hong et al. 2004). Poly(ADPribose)polymerase-1 (PARP-1)-mediated release of apoptosis-inducing factor appears to be an important, recently identified, cell death program. We found increased levels of caspase- 3 and PARP-1 protein expression after 48 -h treatment with either $10^{-6} \mathrm{M}$
OCT or SOM230, showing that SS analogs can induce the activation of both apoptotic pathways. Moreover, the duration and the efficacy of SOM230 on cell growth inhibition, apoptotic induction, and reduction of catecholamine levels were markedly stronger than the effects elicited by OCT. SOM230 at $10^{-7} \mathrm{M}$ was able to inhibit Pheo-c cell growth significantly after 48-h treatment, and by even greater levels after $72 \mathrm{~h}$. This short term as well as the chronic efficacy of SOM230 is probably due to both its improved pharmacodynamic and pharmacokinetic properties.

In conclusion, our results confirm the remarkable heterogeneity of sst expression in neuroendocrine cells. They also demonstrate that OCT and SOM230 are both capable of reducing cell viability and inducing programmed cell death via caspase-3 and PARP-1 apoptotic pathways; however, SOM230 appears to be more effective than OCT. Data in this study add further to the mechanistic insights of SOM230 in PHEO, suggesting a potential role in the diagnostic procedures (as radiolabeled form) and management of the recurrence of this tumors especially in patients at high risk for reintervention.

\section{Acknowledgements}

We are grateful to Dr William J Deery (Rice University, Houston, Texas, USA) for his valuable guidance and editing the manuscript. This work was supported by PRIN 2004, AIRC Regionale to A A S and Fondazione Caripuglia. The authors declare that there is no conflict of interest that would prejudice its impartiality.

\section{References}

Barakat MT, Meeran K \& Bloom SR 2004 Neuroendocrine tumours. Endocrine-Related Cancer 11 1-18.

Bruns C, Raulf F, Hoyer D, Schloos J, Luebbert H \& Weckbecker G 1996 Binding properties of somatostatin receptor subtypes. Metabolism 45 17-20.

Chrisoulidou A, Kaltsas G, Ilias I \& Grossman AB 2007 The diagnosis and management of malignant phaeochromocytoma and paraganglioma. Endocrine-Related Cancer 14 569-585. 
Hannon JP, Nunn C, Stolz B, Bruns C, Weckbecker G, Lewis I, Troxler T, Hurth K \& Hoyer D 2002 Drug design at peptide receptors: somatostatin receptor ligands. Journal of Molecular Neuroscience 18 15-27.

van der Harst E, de Herder WW, Bruining HA, Bonjer HJ, de Krijger RR, Lamberts SW, van de Meiracker AH, Boomsma F, Stijnen T, Krenning EP et al. 2001 [(123)I]metaiodobenzylguanidine and [(111)In] octreotide uptake in benign and malignant pheochromocytomas. Journal of Clinical Endocrinology and Metabolism 86 685-693.

Hong SJ, Dawson TM \& Dawson VL 2004 Nuclear and mitochondrial conversations in cell death: PARP-1 and AIF signaling. Trends in Pharmacological Science 25 259-264.

Invitti C, De Martin I, Bolla GB, Pecori Giraldi F, Maestri E, Leonetti G \& Cavagnini F 1993 Effect of octreotide on catecholamines plasma levels in patients with chromaffin cell tumors. Hormone Research $\mathbf{4 0}$ $156-160$.

Kaltsas G, Korbonits M, Heintz E, Mukherjee JJ, Jenkins PJ, Chew SL, Reznek R, Monson JP, Besser GM, Foley R et al. 2001 Comparison of somatostatin analog and meta-iodobenzylguanidine radionuclides in the diagnosis and localization of advanced neuroendocrine tumors. Journal of Clinical Endocrinology and Metabolism 86 895-902.

Kolby L, Bernhardt P, Johanson V, Wangberg B, Muth A, Jansson S, Forssell-Aronsson E, Nilsson O \& Ahlman H 2006 Can quantification of VMAT and SSTR expression be helpful for planning radionuclide therapy of malignant pheochromocytomas? Annals of the New York Academy of Sciences 1073 491-497.

Kopf D, Bockisch A, Steinert H, Hahn K, Beyer J, Neumann HP, Hensen J \& Lehnert H 1997 Octreotide scintigraphy and catecholamine response to an octreotide challenge in malignant phaeochromocytoma. Clinical Endocrinology 46 39-44.

Koriyama N, Kakei M, Yaekura K, Okui H, Yamashita T, Nishimura H, Matsushita S \& Tei C 2000 Control of catecholamine release and blood pressure with octreotide in a patient with pheochromocytoma: a case report with in vitro studies. Hormone Research 53 46-50.

Kubota A, Yamada Y, Kagimoto S, Shimatsu A, Imamura M, Tsuda K, Imura H, Seino S \& Seino Y 1994 Identification of somatostatin receptor subtypes and an implication for the efficacy of somatostatin analogue SMS 201-995 in treatment of human endocrine tumors. Journal of Clinical Investigation 93 1321-1325.

Lamarre-Cliche M, Gimenez-Roqueplo AP, Billaud E, Baudin E, Luton JP \& Plouin PF 2002 Effects of slow-release octreotide on urinary metanephrine excretion and plasma chromogranin A and catecholamine levels in patients with malignant or recurrent phaeochromocytoma. Clinical Endocrinology 57 629-634.

Mannelli M 2006 Management and treatment of pheochromocytomas and paragangliomas. Annals of the New York Academy of Sciences 1073 405-416.

Mundschenk J, Unger N, Schulz S, Hollt V, Schulz S, Steinke R \& Lehnert H 2003 Somatostatin receptor subtypes in human pheochromocytoma: subcellular expression pattern and functional relevance for octreotide scintigraphy. Journal of Clinical Endocrinology and Metabolism 88 5150-5157.

Pacak K, Eisenhofer G, Ahlman H, Bornstein SR, Gimenez-Roqueplo AP, Grossman AB, Kimura N, Mannelli M, McNicol AM \& Tischler AS 2007 International symposium on pheochromocytoma, pheochromocytoma: recommendations for clinical practice from the First International Symposium. October 2005. Nature Clinical Practice Endocrinology and Metabolism 292-102.
Pasquali D, Vassallo P, Esposito D, Bonavolonta G, Bellastella A \& Sinisi AA 2000 Somatostatin receptor gene expression and inhibitory effects of octreotide on primary cultures of orbital fibroblasts from Graves' ophthalmopathy. Journal of Molecolar Endocrinology 25 63-71.

Pasquali D, Pierantoni GM, Fusco A, Staibano S, Colantuoni V, De Bellis A, Bellastella A \& Sinisi AA 2004 Fenofibrate increases the expression of high mobility group AT-hook 2 (HMGA2) gene and induces adipocyte differentiation of orbital fibroblasts from Graves' ophthalmopathy. Journal of Molecolar Endocrinology 33 133-143.

Patel YC 1999 Somatostatin and ist receptor family. Frontiers in Neuroendocrinology 20 157-198.

Plouin PF, Bertherat J, Chatellier G, Billaud E, Azizi M, Grouzmann E \& Epelbaum J 1995 Short-term effects of octreotide on blood pressure and plasma catecholamines and neuropeptide $\mathrm{Y}$ levels in patients with phaeochromocytoma: a placebo-controlled trial. Clinical Endocrinology 42 289-294.

Plouin PF, Duclos JM, Soppelsa F, Boublil G \& Chatellier G 2001 Factors associated with perioperative morbidity and mortality in patients with pheochromocytoma: analysis of 165 operations at a single center. Journal of Clinical Endocrinology and Metabolism 86 1480-1486.

Scholz T, Eisenhofer G, Pacak K, Dralle H \& Lehnert H 2007 Clinical review: current treatment of malignant pheochromocytoma. Journal of Clinical Endocrinology and Metabolism 92 1217-1225.

Sinisi AA, Bellastella A, Prezioso D, Nicchio MR, Lotti T, Salvatore M \& Pasquali D 1997 Different expression patterns of somatostatin receptor subtypes in cultured epithelial cells from human normal prostate and prostate cancer. Journal of Clinical Endocrinology and Metabolism 82 2566-2569.

Sisson JC \& Shulkin BL 1999 Nuclear medicine imaging of pheochromocytoma and neuroblastoma. Quarterly Journal of Nuclear Medicine 43 217-223.

Soldani C \& Scovassi AI 2002 Poly(ADP-ribose) polymerase-1 cleavage during apoptosis: an update. Apoptosis 7 321-328.

Steinsapir J, Carr AA, Prisant LM \& Bransome ED Jr 1997 Metyrosine and pheochromocytoma. Archive of Internal Medicine 157 901-906.

Tenenbaum F, Lumbroso J, Schlumberger M, Mure A, Plouin PF, Caillou B \& Parmentier C 1995 Comparison of radiolabeled octreotide and meta-iodobenzylguanidine (MIBG) scintigraphy in malignant pheochromocytoma. Journal of Nuclear Medicine 36 1-6.

Unger N, Serdiuk I, Sheu SY, Walz MK, Schulz S, Schmid KW, Mann K \& Petersenn S 2004 Immunohistochemical determination of somatostatin receptor subtypes $1,2 \mathrm{~A}, 3,4$, and 5 in various adrenal tumors. Endocrine Research 4 931-934.

Weckbecker G, Briner U, Lewis I \& Bruns C 2002 SOM 230: a new somatostatin peptidomimetic with potent inhibitory effects on the growth hormone/insulin-like growth factor-I axis in rats, primates, and dogs. Endocrinology 143 4123-4130.

Zatelli MC, Piccin D, Bondanelli M, Tagliati F, De Carlo E, Culler MD \& Uberti EC 2003 An in vivo OctreoScan-negative adrenal pheochromocytoma expresses somatostatin receptors and responds to somatostatin analogs treatment in vitro. Hormone and Metabolic Research 35 349-354.

\section{Received in final form 13 March 2008 \\ Accepted 1 April 2008}

Made available online as an Accepted Preprint 1 April 2008 